\title{
Pause and rate effects in multiple-reinforcement fixed ratio schedules'
}

DONALD E. MINTZ, DENNIS J. MOURER AND LAURA S. WEINBERG

THE CITY COLLEGE OF THE CITY UNIVERSITY OF NEW YORK

Fixed ratio schedules were employed in which the number of unreinforced responsed per reinforced sequence was kept constant but the number of successive reinforced responses was systematically varied from one to four. Both higher run rates and shorter pauses in responding following reinforcement were related to greater numbers of reinforcements for the pigeons used in this study. With more than one reinforcement the post-reinforcement pause was frequently preceded by a short burst of responses.

Several studies suggest that the rate of simple operant responding is not consequentially affected by the magnitude of individual reinforcements (Keesey \& Kling, 1961; Catania, 1963). Particularly when every $\mathrm{n}^{\text {th }}$ response is reinforced (fixed ratio-FR) the rate of response, once responding is initiated appears relatively invariant (Sidman \& Stebbins, 1954; Ferster \& Skinner, 1957). Conversely, the pause in responding that characteristically follows reinforcement has been shown subject to variation by a wide variety of parameters. Following a procedure described by Mintz (1962) the present study examines the pausing and response rate variations produced by FR schedules in which the experimental variable is the number of reinforced responses following fixed-length unreinforced response sequences.

\section{Method}

Two adult male white Carneaux pigeons were run in a standard Lehigh Valley two-key operant test chamber with only the right-hand key in operation. The birds were maintained at $80 \%$ of their ad lib feeding weight. Three to five conditioning sessions were conducted weekly over a period of approximately one year.

Reinforcement for the key-peck response was $3.5 \mathrm{sec}$. access to feed. At different stages of the experiment different numbers of successive responses were reinforced following each unreinforced response sequence. The unreinforced sequences involved 125 responses for S1 and 85 for S2. Each bird performed on schedules in which one, two, three or four successive responses were reinforced at the end of each unreinforced sequence. Each schedule was kept constant until stable performance was observed, typically two to three months of training. S1 began training with four consecutive reinforced responses in each FR cycle; the subsequent schedules involved three, two and one reinforcements in that order. An ascending sequence was employed for S2. After completing the sequence of four schedules each bird was returned to its initial schedule and S1 was further returned to a one reinforcement schedule. Daily sessions involved 25 to $50 \mathrm{FR}$ cycles.

\section{Results and Discussion}

For both Ss the rate of response showed a general increase with an increase in the number of reinforcements. For S2 the overall effects were regular and monotonic; for S1 the general effects appeared to be a dichotomy, rate of response with one reinforcement notably lower than the multiple-reinforcement conditions but irregular differences among the latter. Variation in the rate of response was observed for both the duration of post-reinforcement pausing and the elapsed time for the run of responses preceding reinforcement. Measures of both aspects of the behavior are shown in Fig. 1. For clarity only the one- and fourreinforcement conditions are represented. The curves in Fig. 1 are relative frequency distributions of the elapsed time for the "start" of the FR cycle (termination of the last reinforcement to completion of the 10th response) and the "end" of the FR cycle (10th through 125th response for $S 1 ; 10$ th through 85th response for S2). The start-of-cycle measure subsumes whatever post-reinforcement pausing occurred.

For the analysis of pausing, any 5-sec. period of non-response (other than during reinforcement) was defined as a pause. In the conventional FR contingency, such pausing is almost always restricted to the period immediately following reinforcement. With FR schedules involving multiple reinforcements, some unusual pause variations are observed. Figure 2 shows the relative frequency with which a pause in responding immediately followed the final reinforcement of the reinforced sequence (discriminative pausing) as a function of the length of that sequence. With multiple

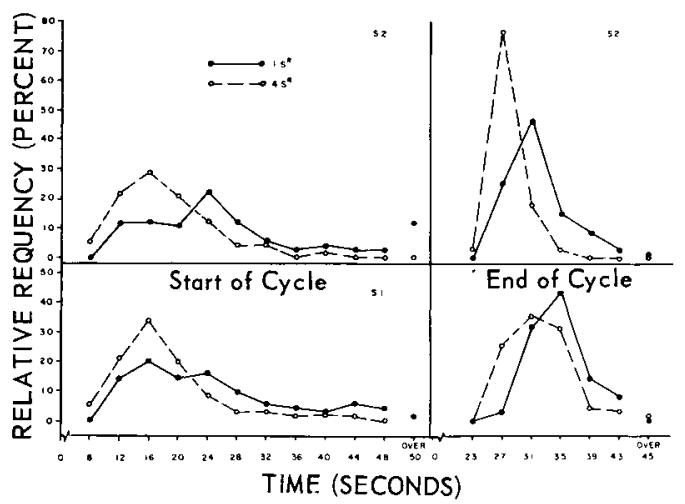

Fig. 1. Relative frequency distributions of elapsed time from end of reinforcement to $10^{\text {th }}$ response ("start"), and $10^{\text {th }}$ response to next reinforcement ("end"). 
reinforcements the pause following reinforcement was frequently preceded by a short burst of responses. The tendency for this behavior regularly increased with an increase in the number of reinforcements, reflected in Fig. 2 by the decrease in pausing immediately following reinforcement.

Each introduction of a new schedule led to pronounced pause variations. Sample cumulative records of such transitions for both Ss are shown in Fig. 3. Among the response variations that may be noted for the initial exposures are cycles with no pausing at all, pauses between reinforcements, irregular response rates at the beginning of response runs, and pauses displaced considerably upward from the reinforcements marked on the records. In general, progressive training on a new schedule produced a shift in pausing, characterized by greater regularity and closer proximity to the preceding reinforcement. Where the new schedule involved a single reinforcement, a few days' training generally brought the pausing to the point in time immediately following reinforcement. With multiple reinforcements, a short burst of responses frequently continued to precede any pause.

The data of this study provide further evidence that FR pausing is controlled by the advent of cues correlated with the initiation of a non-reinforced response sequence. When a single reinforcement is employed, the occurrence of reinforcement appears adequate to provide this control. Reinforcement followed by nonreinforcement often seems necessary to produce a pause when multiple reinforcements are used. The change to a new schedule tends to exaggerate these conditions. Whatever discrimination of number or "counting" established, no longer relates to the new reinforcement conditions. Non-reinforcement following reinforcement remains the only event at the beginning of the non-reinforced sequence that is common to the

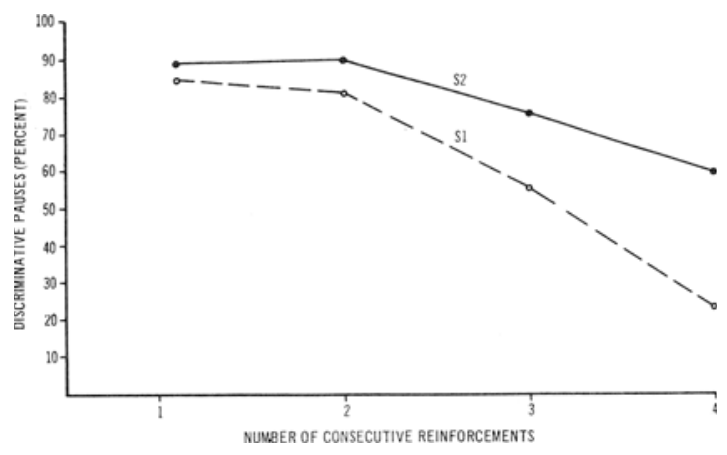

Fig. 2. Percent of pauses immediately preceding first unreinforced response as a function of number of consecutive reinforcements.

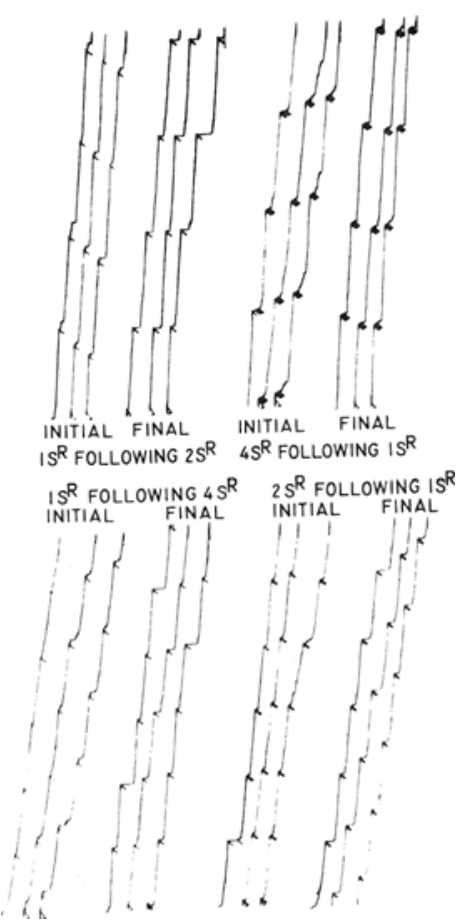

Fig. 3. Cumulative response records for transitions to schedules with different numbers of consecutive reinforcement. Curves represent initial and final stable performance on the schedules. Upper curves for $\mathrm{S1}$; lower for $\mathrm{S} 2$.

several schedules employed, and the pause occurs in this context.

The present study also suggests that FR response rate is subject to variation under some conditions. However, the parameters that distinguish invariant from modifiable terminal FR run rates require further analysis.

\section{References}

Catania, A. C. Concurrent performances: A baseline for the study of reinforcement magnitude. J. exp. Anal. Behav., 1963, 6, 299 300 .

Ferster, C. B., \& Skinner, B. F. Schedules of reinforcement. New York: Appleton-Century-Crofts, 1957.

Kessey, R. E., \& Kling, J. S. Amount of reinforcement and freeoperant responding. J. exp. Anal. Behav., 1961, 4, 125-132.

Mintz, D. E. Force of response during ratio reinforcement. Science, $1962,138,516-517$.

Sidman, M., \& Stebbins, W. C. Satiation effects under fixed-ratio schedules of reinforcement. J. comp. physiol. Psychol., 1954, 47, 114-116.

\section{Note}

1. This research was supported in part by a grant from HoffmannLa Roche, Inc. 